\title{
Commentary Novel biomarkers in critical care: utility or futility?
}

\section{Gareth L Ackland ${ }^{1}$ and Michael G Mythen ${ }^{2}$}

\author{
${ }^{1}$ Centre for Anaesthesia, Critical Care and Pain Management, University College London \\ ${ }^{2}$ Smiths Medical Chair of Anaesthesia and Critical Care, University College London
}

Corresponding author: Gareth L Ackland, g.ackland@ucl.ac.uk

Published: 7 November 2007

Critical Care 2007, 11:175 (doi:10.1186/cc6127)

This article is online at http://ccforum.com/content/11/6/175

(c) 2007 BioMed Central Ltd

See related research by Fellahi et al., http://ccforum.com/content/11/5/R106

\begin{abstract}
One of the holy grails of modern medicine, across a range of clinical sub-specialties, is establishing highly sensitive and specific biomarkers for various diseases. Significant success has been achieved in some of these clinical areas, most notably identifying high-sensitivity $\mathrm{C}$-reactive peptide, troponin $\mathrm{I} / \mathrm{T}$ and brain natriuretic peptide as significant prognosticators for both the acute outcome and the development of cardiovascular pathology. However, it is highly debatable whether this translates to complex, multi-system pathophysiological insults. Is critical care immune from the application of these novel biomarkers, given the numerous confounding factors interfering with their interpretation?
\end{abstract}

In the previous issue of Critical Care [1], Fellahi and colleagues, in a large observational study, describe troponin-I release in three cohorts of cardiac surgical patients undergoing bypass grafts, valve replacement(s) or both. They report that patients undergoing both valve and bypass graft procedures sustained more cardiac damage, but the troponin-threshold for clinically significant events was higher in these patients. There are no cardiac tissue samples or serial echocardiographic data to provide histopathological and/or physiologic corroboration of these findings. On face value these results are perhaps not surprising, given that intuitively greater cardiac tissue damage, longer bypass time and hence a larger inflammatory stimulus would be predicted for patients undergoing valvular replacement alone or the dual procedure. Nevertheless, these are valuable data in that they illustrate some of the complexities surrounding troponin, a justifiably established star of the new biomarker age, in the sphere of critical care. The limitations of troponin, including the lack of universal measurement standards and its interpretation in the critically ill patient have been discussed in detail in this journal recently [2]. A key issue surrounding the utility of troponin remains the mechanism(s) of myocardial injury in both the cardiac surgical and critically ill patient which, despite the high incidence reported in several critical care studies over the last 10 years, continues to elude workers in this field.

Unsurprisingly, other novel biomarkers that have strikingly similar utility in specific patient populations (most notably cardiac failure) have failed to evade the attention of critical care clinical researchers. Recently, conflicting data have emerged for brain natruretic peptide (BNP) in sepsis [3,4], an otherwise excellent specific biomarker for the cardiac failure population [5]. An often overlooked reason for this dichotomy is the fundamentally altered pharmaco-physiology of the critically ill patient. An elegant example is served by the finding that lipopolysaccharide induces BNP expression independently in a cultured cardiac myocyte model, free of haemodynamic perturbations [6]. Thus, a significant component of the elevation in BNP in septic patients may be a consequence of invasive bacterial infections and/or gutderived endotoxin, both unrelated to primary haemodynamic impairment. Other important triggers for BNP expression are mediated through mitogen activated protein (MAP) kinase pathways [7], including cytokines, beta and particularly alpha adrenergic agonists [8]. These important laboratory findings clearly highlight whether novel biomarkers like BNP and troponin are merely demonstrating the sequelae of our current treatment regimes for critically ill patients. Untangling the relationship between primary pathology, its biomarkers and the consequences of treatment/processes that drive that biomarker expression further is a recurring hurdle that may prove insurmountable. Nevertheless, the essential question that many of the new wave of critical care biomarker studies present is whether the results of these tests, assuming they are specific and sensitive, would alter our management of the critically ill patient fundamentally. So far, there have been no interventional studies based on the measurement of such

$\mathrm{BNP}=$ brain natruretic peptide $\mathrm{MAP}=$ mitogen activated protein. 
novel biomarkers in the general critically ill population. This would seem a crucial step to justify the continued efforts in defining what elevations of various biomarkers mean. Furthermore, the combined number of patients studied in the critical care biomarker literature is severalfold smaller than those conducted in limited or single-organ, clearly defined, often subtle/pre-clinical disease states, where tens of thousands of patients have been recruited [9]. Importantly, the utility (and basic scientific understanding) of many of these novel biomarkers has been reinforced by predictable changes in their levels upon specific, clinically relevant and successful interventions [9,10]. Again, this is a major challenge given the complexity, and relatively poor outcomes, associated with the critically ill patient. Just as single interventions have failed to alter outcomes in severe sepsis, it seems highly unlikely that the measurement of biomarkers in isolation from an associated "package of care" will alter critical care outcomes. This serves to remind us of the importance of large population clinical research in critical care medicine and the dangers of extrapolating populationcentred, relatively uncomplicated, limited, single-organ pathophysiology to the critically ill patient. However, defining subsets of critical care patients to explore these hypotheses may be fruitful. For example, elevated preoperative levels of high sensitivity C-reactive peptide and BNP are associated with poorer postoperative outcome, albeit in small studies thus far [11,12]. Perhaps stratifying postoperative critical care using these new biomarkers, well before complex inflammatory and septic pathophysiological alterations escalate, will become an important economic and clinical contribution that further research can make.

\section{Competing interests}

The authors declare that they have no competing interests.

\section{References}

1. Fellahi JL, Hedoire F, Le Manach Y, Monier E, Guillou L, Riou B: Determination of the threshold of cardiac troponin I associated with an adverse postoperative outcome after cardiac surgery: a comparative study between coronary artery bypass graft, valve, and combined cardiac surgery. Crit Care 2007, 11:R106.

2. Collinson P, Gaze D. Cardiac troponins in intensive care. Crit Care 2005, 9:345-346.

3. Rudiger A, Gasser S, Fischler M, Hornemann T, von Eckardstein $\mathrm{A}$, Maggiorini $\mathrm{M}$ : Comparable increase of $\mathrm{B}$-type natriuretic peptide and amino-terminal pro-B-type natriuretic peptide levels in patients with severe sepsis, septic shock, and acute heart failure. Crit Care Med 2006, 34:2140-2144.

4. Varpula M, Pulkki K, Karlsson S, Ruokonen E, Pettilä V; FINNSEP. SIS Study Group: Predictive value of $\mathrm{N}$-terminal pro-brain natriuretic peptide in severe sepsis and septic shock. Crit Care Med 2007, 35:1277-1283.

5. Baughman KL: B-type natriuretic peptide - A window to the heart. N Engl J Med 2002, 347:158-159.

6. Tomaru Ki K, Arai M, Yokoyama T, Aihara Y, Sekiguchi Ki K, Tanaka T, Nagai R, Kurabayashi M: Transcriptional activation of the BNP gene by lipopolysaccharide is mediated through GATA elements in neonatal rat cardiac myocytes. J Mol Cell Cardiol 2002, 34:649-659.

7. LaPointe MC: Molecular recognition of the brain natriuretic peptide gene. Peptides 2005, 26:944-956.

8. Hanford DS, Thuerauf DJ, Murray SF, Glembotski CC: Brain natriuretic peptide is induced by alpha 1 -adrenergic agonists as a primary response gene in cultured rat cardiac myocytes. $J$ Biol Chem 1994, 269:26227-26233.

9. Ridker PM: C-reactive protein and the prediction of cardiovascular events among those at intermediate risk: moving an inflammatory hypothesis toward consensus. J Am Coll Cardiol 2007, 49:2129-2138.

10. Troughton RW, Frampton CM, Yandle TG, Espiner EA, Nicholls MG, Richards AM: Treatment of heart failure guided by plasma aminoterminal brain natriuretic peptide (N-BNP) concentrations. Lancet 2000, 355:1126-1130.

11. Ackland GL, Scollay JM, Parks RW, de Beaux I, Mythen MG: Preoperative high sensitivity $\mathrm{C}$-reactive protein and postoperative outcome in patients undergoing elective orthopaedic surgery. Anaesthesia 2007, 62:888-894

12. Sear JW, Howard-Alpe G: Preoperative plasma BNP concentrations: do they improve our care of high-risk non-cardiac surgical patients? Br J Anaesth 2007, 99:151-154. 